\title{
Minireview
}

\section{The clinical potential of antiangiogenic fragments of extracellular matrix proteins}

\author{
AR Clamp*,I and GC Jayson' \\ 'Cancer Research UK Department of Medical Oncology, Christie Hospital, Wilmslow Road, Manchester M20 4BX, UK
}

\begin{abstract}
Neovasculature development is a crucial step in the natural history of a cancer. While much emphasis has been placed on proangiogenic growth factors such as VEGF, it is clear that endogenous angiogenesis inhibitors also have critical roles in the regulation of this process. Recent research has identified several cryptic fragments of extracellular matrix/vascular basement membrane proteins that have potent antiangiogenic properties in vivo. It has become apparent that many of these fragments signal via interactions with endothelial integrins, although multiple downstream effector pathways have been implicated and endostatin, the first non-collagenous domain of collagen XVIII, influences an intricate signalling network. The activity of these molecules in animal models suggests that they may have significant clinical activity; however, results of phase I/II trials with endostatin were disappointing. Many possible reasons can be found for the failure of these studies. Weaknesses in trial design, endostatin administration regimen and patient selection are identifiable, and importantly the lack of a clearly defined antiangiogenic mechanism for endostatin hindered assessment of biologically effective dose. Additionally, in vivo immunological and proteolytic function-neutralising mechanisms may have negated endostatin's actions. Lessons learned from these studies will aid the future clinical development of other antiangiogenic extracellular matrix protein fragments.
\end{abstract}

British Journal of Cancer (2005) 93, 967-972. doi: I 0.I038/sj.bjc.6602820 www.bjcancer.com

Published online 18 October 2005

(c) 2005 Cancer Research UK

Angiogenesis, the development of a neovasculature from preexisting blood vessels, is vital for tumour growth and metastasis. Without a blood supply, neoplastic deposits remain dependent on diffusion for nutrients, oxygenation and the removal of waste metabolites. Their growth is restricted to a maximum of $1-2 \mathrm{~mm}^{3}$ and most remain clinically quiescent.

Interactions between endothelial cells and the extracellular matrix (ECM), in particular components of the vascular basement membrane (VBM), play key roles in the regulation of angiogenesis (Kalluri, 2003). The VBM is constructed from interacting but independent scaffolds of laminins and collagen IV complemented by many other important but less abundant molecules such as perlecan, the fibulins and collagens XV and XVIII. These molecules contribute to the control of endothelial cell development, proliferation, migration and function via interactions with transmembrane signalling molecules such as the integrins and syndecans.

While tumour angiogenesis is characterised by the secretion of a multiplicity of proangiogenic factors tripping the angiogenic switch resulting in the development of a structurally and functionally abnormal vasculature, physiological angiogenesis is tightly controlled and, in most tissues, proangiogenic factors are balanced by endogenous antiangiogenic signals holding the angiogenic switch 'off' (Carmeliet and Jain, 2000).

*Correspondence: Dr AR Clamp; E-mail: aclamp@picr.man.ac.uk Received 28 June 2005; revised 19 September 2005; accepted 22 September 2005; published online 18 October 2005
Recently, several ECM/VBM protein fragments have been isolated that have potent antiangiogenic properties that are only apparent after proteolytic cleavage of the fragments from their parental molecule. These cryptic endogenous angiogenesis inhibitors (Nyberg et al, 2005) specifically inhibit endothelial cell proliferation and migration in vitro and also have impressive antitumour activity in vivo (O'Reilly et al, 1997; Hamano et al, 2003; Bix et al, 2004). These findings led to considerable enthusiasm for the clinical investigation of the fragments. However, this excitement has subsequently been tempered by the results obtained in early phase trials of endostatin, a C-terminal proteolytic fragment derived from the first non-collagenous (NC1) domain of collagen XVIII (O'Reilly et al, 1997).

In this review, we will briefly describe the antiangiogenic fragments of ECM proteins and then discuss the endostatin trials focusing on what lessons can be learnt to aid us in the clinical development of other endogenous angiogenesis inhibitors.

\section{MECHANISMS OF ACTION - SIMILARITIES AND DIFFERENCES}

Since Homandberg et al (1985) isolated 29 and $40 \mathrm{kDa}$ fibronectin fragments that could inhibit endothelial cell proliferation (Homandberg et al, 1985), a substantial number of antiangiogenic ECM protein fragments have been identified and these are summarised in Table 1.

The most thoroughly investigated group of ECM fragments are those derived from the first non-collagenous (NC1) domains of VBM collagens - in particular, endostatin (O’Reilly et al, 1997) and 
Table I Proteolytic fragments of ECM components with antiangiogenic properties

\begin{tabular}{|c|c|c|c|}
\hline Proteolytic fragment & ECM protein & Putative cell surface receptors & Possible mechanisms of action \\
\hline Arresten & $\alpha \mid$ collagen IV & $\alpha|\beta|$ integrin and HSPG & Interference with Ras-Shc-MAPK signalling \\
\hline$\alpha 6 \mathrm{NCl}$ & $\alpha 6$ collagen IV & $\alpha \vee \beta 3$ integrin & ND \\
\hline Endostatin & $\alpha \mid$ collagen $X V I I I$ & $\alpha 5 \beta \mid$ integrins and HSPGs & See text \\
\hline Restin & $\alpha \mid$ collagen $X V$ & ND & ND \\
\hline \multicolumn{4}{|l|}{ Other ECM proteins } \\
\hline Anastellin & First type III repeat of fibronectin & ND & Inhibition of ERK signalling \\
\hline Endorepellin & Perlecan & $\alpha 2 \beta \mid$ integrin & Upregulation of PKA and FAK activity \\
\hline TSP-I fragments & Thrombospondin-I & CD36/ $\beta 1$-integrins & Inhibition of PI3K \\
\hline PEX & MMP-2 & $\alpha \vee \beta 3$ integrin & Blocks cell surface activity of MMP-2 \\
\hline
\end{tabular}

$\mathrm{ECM}=$ extracellular matrix; HSPG = heparan sulphate proteoglycan; MAPK = mitogen-activated protein kinase; PI3K = phosphatidylinositol-3 kinase; ND = not defined; $\mathrm{ERK}=$ extracellular signal-regulated kinase; $\mathrm{FAK}=$ focal adhesion kinase; PKA = protein kinase A; MMP-2 = matrix metalloproteinase-2; Nyberg et al (2005) and references therein.

tumstatin (Maeshima et al, 2001; Hamano et al, 2003), derived from the $\alpha 1$ chain of collagen XVIII and $\alpha 3$ chain of collagen IV, respectively. These globular, relatively protease-resistant domains are released from the VBM by the action of proteolytic enzymes at a protease-sensitive hinge region. While several proteases, including elastase and cathepsin L, have been shown to induce endostatin release in vitro, matrix metalloprotease-9 (MMP-9) appears to generate tumstatin in vivo, as MMP-9 knockout mice have lower circulating levels of tumstatin. Tumour xenografts exhibit rapid growth with increased angiogenesis in these mice in a manner that can be prevented by restoring 'physiological' serum tumstatin levels (Hamano et al, 2003).

Recent research has identified that integrins on the endothelial cell surface act as signal transducing receptors for many ECM proteolytic fragments (Table 1). Endothelial cells express multiple integrins but $\alpha \mathrm{v} \beta 3$ and $\alpha 5 \beta 1$ are substantially upregulated in activated endothelia and antagonists of these transmembrane receptors can suppress angiogenesis in vivo (summarised in Jin and Varner, 2004). Tumstatin binds $\alpha \mathrm{v} \beta 3$ integrin and endostatin binds $\alpha 5 \beta 1$, resulting in inhibition of downstream focal adhesion kinase activation (Sudhakar et al, 2003) although the antiangiogenic effector pathways are distinct for each molecule. Tumstatin inhibits CAP-dependent protein translation via phosphatidylinositol-3 kinase (PI3K)/Akt/mTOR and 4E-BP1, resulting in endothelial cell apoptosis (Maeshima et al, 2001; Sudhakar et al, 2003). Endostatin, however, modulates focal adhesion and actin stress fibre formation. In human dermal microvascular cells (HDMECs), endostatin induces clustering of $\alpha 5 \beta 1$ integrins within lipid raft microdomains in a manner that is dependent on cell surface heparan sulphate proteoglycans (HSPGs). This clustering activates Src kinases that downregulate RhoA activity, so dissociating focal adhesions and actin stress fibres and inhibiting endothelial cell migration (Wickström et al, 2003). Notably, the addition of a second integrin-binding site to the $\mathrm{N}$-terminal of endostatin appears to increase its antiangiogenic potency (Yokoyama and Ramakrishnan, 2004).

While this signalling pathway for endostatin has been well elucidated, multiple other potential antiangiogenic mechanisms and ligands for endostatin have been described. These include direct interaction with cell surface KDR (Kim et al, 2002) and glypican HSPGs (Karumanchi et al, 2001), binding to tropomyosin isoform 3 (MacDonald et al, 2001), inhibition of MMP-2 (Lee et al, 2002) and downregulation of $\beta$-catenin via Wnt signalling pathways (Hanai et al, 2002). Notably, examination of the downstream effects of endostatin in HDMECs by gene expression profiling and phosphoproteomics (Abdollahi et al, 2004) detected the coordi- nated regulation of eight angiogenic effector pathways with the expression of $12 \%$ of assessed genes being altered at least two-fold after $2 \mathrm{~h}$ endostatin exposure. Although this investigation gives us just a snapshot of the in vitro effects of a fixed concentration of endostatin at a single time point in one endothelial cell line, it demonstrates that endostatin influences a remarkable and intricate signalling network in order to assert its antiangiogenic effects. Clearly, further work needs to be performed to validate the data and explore what factors allow endostatin to target tumour endothelial cells specifically in animal models without adversely affecting physiological angiogenesis. Similar investigations with other ECM angiogenesis inhibitors may identify further similarities or differences to endostatin, which could direct the development of combination antiangiogenic approaches.

\section{A PHYSIOLOGICAL ROLE?}

Although a substantial body of evidence now exists to support an antiangiogenic role for pharmacological doses of ECM fragments in experimental systems, data indicating a physiological role for these molecules are scarce. Endostatin is present at detectable levels in the serum of normal individuals (Feldman et al, 2002; IIzasa et al, 2004) and canstatin/arresten has been isolated from human placenta, suggesting physiological function. Further indirect evidence is provided by the study of mouse strains with null mutations in the parental ECM molecule and rare single gene disorders in humans (see Table 2). While these models implicate ECM fragments such as endostatin and restin in vascular development in specific organs, it appears that in the majority of tissues there is 'physiological redundancy' with the absence of a single fragment compensated for by other proteins.

Importantly however, Sund et al (2005) recently presented evidence suggesting that tumstatin, endostatin and thrombospondin-1 have endogenous tumour suppressor functions. Using tumstatin- and endostatin-deficient mouse strains, they documented accelerated growth of Lewis lung carcinoma/B16F10 melanoma xenografts compared to identical tumours in the parental mouse lines. Notably, tumour growth was even more rapid in mice deficient in both tumstatin and thrombospondin-1, indicating that these three molecules suppress the growth of tumour xenografts when present at physiological concentrations. This observation was reinforced by the observation that B16F10 xenograft growth was suppressed in a mouse line engineered to overexpress endostatin resulting in a 1.6-fold increase in circulating endostatin levels. This latter model recapitulates the clinical observation that 
Table 2 Phenotypic manifestations associated with the deletion of ECM proteins

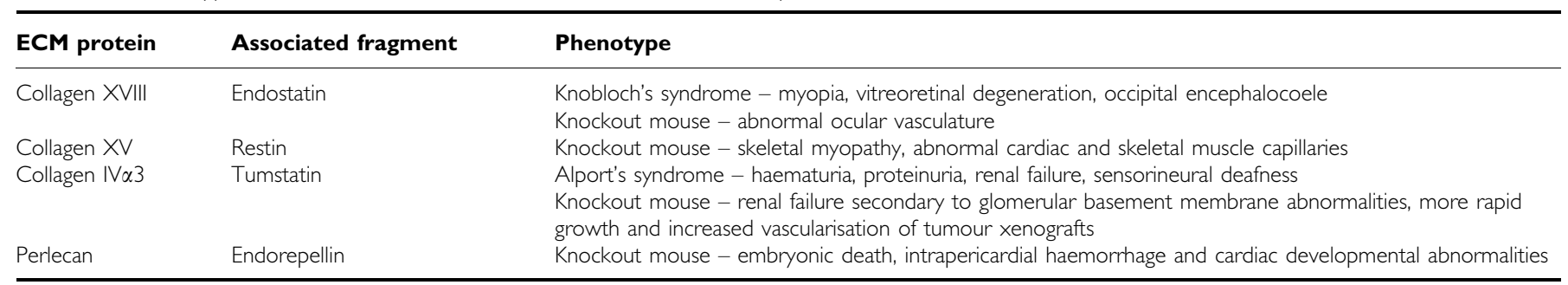

$\mathrm{ECM}=$ extracellular matrix; Hudson et al (2003), Marneros and Olsen (2005) and Nyberg et al (2005).

patients with Down's syndrome (trisomy 21) who have three copies of the collagen XVIII gene and $70 \%$ higher serum endostatin levels (Zorick et al, 2001) have much lower standardised mortality odds ratios for death from solid malignant tumours at all ages than the rest of the population (Yang et al, 2002), suggesting that endostatin may have an endotheliumspecific tumour suppressor function in humans.

\section{CLINICAL STUDIES}

While most antiangiogenic ECM fragments have yet to enter clinical development, three phase I trials have been published using recombinant human endostatin in a total of 61 patients with advanced metastatic cancer (including 11 melanoma, 10 sarcoma, nine colorectal, nine lung, seven breast, four renal) (Eder et al, 2002; Herbst et al, 2002a; Thomas et al, 2003). These studies administered daily endostatin doses of $15-600 \mathrm{mg} \mathrm{m}^{-2}$ day $^{-1}$ by short intravenous infusion. No significant endostatin-related toxicity was noted. Endostatin displayed consistent linear pharmacokinetics with the area under the serum concentration-time curve reaching levels associated with activity in animal models, at doses of $300 \mathrm{mg} \mathrm{m}^{-2} \mathrm{day}^{-1}$. No formal disease responses were seen although some evidence of antineoplastic activity was noted with one patient with metastatic pancreatic neuroendocrine tumour experiencing a minor response (Eder et al, 2002). However, these suggestions of antitumour activity did not appear to be doserelated and a subsequent phase II study of twice daily subcutaneous endostatin in metastatic neuroendocrine tumours only documented two minor responses in 41 patients (Kulke et al, 2003).

One problem for the phase I development of all antiangiogenic agents, which is exemplified by endostatin, is the difficulty in establishing the biologically effective dose (BED). All three phase I studies utilised radiological and biopsy-based indicators of tumour angiogenesis to assess BED. Thomas et al (2003) failed to demonstrate any significant changes by in vivo imaging with dynamic CT (marker of microvessel density), dynamic MRI (marker of tumour blood flow) or $\left[{ }^{18} \mathrm{~F}\right]$ FDG PET (measure of tumour glucose metabolism). No changes in microvessel density, endothelial cell apoptosis, proliferation or vessel maturity were seen in paired pre- and 8-week post-treatment tumour biopsies from patients in this study although only eight sample pairs were available for analysis.

Herbst et al (2002b), however, in their study of 26 patients detected complex effects on tumour blood flow and biopsy biomarkers of tumour angiogenesis. Utilising $\left[{ }^{15} \mathrm{O}\right] \mathrm{H}_{2} \mathrm{O}$ PET, they noted that blood flow decreased by an average of $20 \%$ with endostatin treatment by day 28 at the $180 \mathrm{mg} \mathrm{m}^{-2}$ day $^{-1}$ dose level. Subtle changes in intratumoral glucose metabolism were also noted at higher endostatin doses. Changes in intratumoral blood flow only reached statistical significance however if patients treated at the $30 \mathrm{mg} \mathrm{m}^{-2}$ day $^{-1}$ dose level were included. These patients did not have baseline PET imaging and so changes during cycle 2 instead of cycle 1 were used in the assessment of this cohort. Tumour biopsy analysis for microvessel density, endothelial cell apoptosis and nuclear localisation of HIF- $1 \alpha$ as a marker of tumour hypoxia also suggested that endostatin was having an in vivo biological effect on human cancer (Davis et al, 2004). Intriguingly, statistical analysis using the quadratic polynomial model indicated that these effects may have a U-shaped relationship with dose, being most apparent around $250 \mathrm{mg} \mathrm{m}^{-2}$ day $^{-1}$. While such exploratory analyses give us a potential insight into a BED for endostatin, they should be interpreted cautiously for several reasons. It is possible that the analysis employed was highly dependent on the range of doses used and may be distorted by the presence of outlying values. Seven patients $(28 \%)$ with early progressive disease on study were excluded from these analyses owing to a lack of post-treatment biopsies and most importantly, these signs of biological activity were not translated into clinical activity. It is also impossible to rule out a contribution of tumour biology to the changes documented as no information is available on the natural history of these parameters in untreated malignancy.

\section{WHAT CAN BE LEARNED FROM THE ENDOSTATIN TRIALS?}

Although the studies discussed above confirmed the safety of endostatin as a pharmacological agent, the lack of antineoplastic and antiangiogenic activity was disappointing. What lessons can be drawn from these studies for the future clinical development of endostatin and other endogenous angiogenesis inhibitors?

\section{Appropriate trial design, administration regimen and patient selection}

Conventionally, most phase I studies are conducted in patients with bulky chemotherapy-resistant metastatic disease. Such patients are not ideal for the assessment of antiangiogenic agents, as not only do the tumours already have an established vasculature but the cancer cells are likely to have become tolerant of hypoxia and other apoptosis-inducing signals. It may be more appropriate, once toxicity data are available, to assess these agents in patients with minimal residual disease.

Endostatin was administered as short daily intravenous infusions in the published phase I studies. However, initial animal data were generated using the subcutaneous administration of a poorly soluble form of endostatin that is likely to have acted as a depot (O'Reilly et al, 1997) and subsequent work has shown that continuous infusion of endostatin is markedly more effective than bolus administration in animal models (Kisker et al, 2001). The most efficacious preclinical regimen should be adopted in clinical studies if feasible.

Tumour response may also be an inappropriate end point in phase II studies of endogenous angiogenesis inhibitors, as such molecules may only result in disease stabilisation. Trial designs 
assessing time to disease progression such as the randomised discontinuation model (Rosner et al, 2002) may be more sensitive to a biological effect.

\section{Clear understanding of antiangiogenic mechanism}

At the time of the design of the endostatin trials, very little was known about endostatin's mechanisms of action. This clearly inhibited the scope of biomarker/translational research undertaken. The complexity of signalling pathways modulated by endostatin in endothelial cells in vitro means that no single biomarker can be proposed with certainty for investigation in future trials although assessment of $\alpha_{5} \beta_{1}$ integrin expression and downstream signalling should be considered. The emerging evidence for a role of cell surface HSPGs in endostatin's function means that the use of heparin, particularly as a line-lock, may have abrogated its clinical activity. Such treatment was specifically contra-indicated in only one trial (Herbst et al, 2002a).

The clearly defined antiangiogenic mechanism for tumstatin indicates that assessment of $\mathrm{PI} 3 \mathrm{~K}-\mathrm{mTOR}-4 \mathrm{E}-\mathrm{BP} 1$ pathway in tumour endothelial cells should be included as a pharmacodynamic end point in any phase I tumstatin trials.

\section{Immunogenicity, intravascular proteolysis and a potential platelet sink}

The administration of exogenous protein is associated with an immunogenic risk. Although no significant allergic reactions were seen with endostatin, many patients rapidly developed antiendostatin IgG titres (Eder et al, 2002; Herbst et al, 2002a). Whether these antibodies are function-neutralising is not clear but their rapid induction is concerning.

Another immunological factor that may impinge on the clinical development of tumstatin is the localisation of the epitope recognised by the pathogenic auto-antibodies for Goodpasture's syndrome (GPS), a condition characterised by rapidly progressive glomerulonephritis and pulmonary haemorrhage, at the $\mathrm{N}$ terminus of the tumstatin domain of $\alpha 3$ collagen IV (Hudson et al, 2003).

The potential clearance of circulating proteins by plasma and ECM proteases is a concern with all endogenous antiangiogenics. Although pharmacokinetic data were linear and analysis of serumisolated endostatin in one phase I study (Thomas et al, 2003) did not demonstrate extensive proteolytic degradation, small shifts in mass spectrometry profiles were noted that could be consistent with limited terminal proteolytic cleavage. Of note, no in vitro activity could be demonstrated for re-isolated endostatin in any of the three studies.

In addition, platelets sequester many angiogenic regulators and have recently been shown to take up endostatin in a selective and quantifiable manner (Klement et al, 2004). This may indicate that the circulating platelet mass may need to become saturated with exogenously administered endostatin before it is able to target endothelial cells.

\section{OTHER POTENTIAL HURDLES}

\section{Vasculogenic mimicry}

Many established tumours have blood vessels lined in part or completely by tumour cells. In some cases, these cells express surface markers normally confined to endothelial cells. Tubular network formation by such cell lines is unaffected by endostatin treatment and other angiogenesis inhibitors (van der Schaft et al, 2004 ), indicating that the vascularity of some tumours may not be altered even if optimal inhibition of endothelial cell function is achieved in vivo. Some lung carcinomas also co-opt the host's existing alveolar capillary network. They are therefore less reliant on neoangiogenesis and unlikely to be sensitive to antiangiogenic therapies (Pezzella et al, 1997).

\section{Targeting an already overloaded system}

Elevated serum endostatin concentration is seen in many untreated cancer patients and has been identified as an adverse prognostic factor. It is unclear whether these elevated endostatin levels are due to direct intratumoral production or a coordinated 'host' response to proangiogenic stimuli, in particular VEGF produced by the cancer (Feldman et al, 2002; Glenjen et al, 2002; Iizasa et al, 2004). What such findings do suggest however is that if this endogenous endostatin is in an active form, further increasing serum endostatin levels to pharmacological levels may not have a significant additional antiangiogenic effect as it is possible that in clinically manifest tumours, once the angiogenic switch has been tripped, raising the levels of endogenous antiangiogenic agents further is not very effective in resetting this. A further alternative explanation is that in effect these cancers are already at the top of the dose-response curve for endostatin and so have overcome its inhibitory effects. This possibility would have significant implications for the use of ECM proteolytic fragments as single agents in the therapeutic setting.

\section{FUTURE DIRECTIONS}

\section{Rational combinations}

Preclinical studies have demonstrated that the antitumour effects of endostatin are additive to radiotherapy (Shi et al, 2003) and synergistic with cytotoxic chemotherapy (Plum et al, 2003) in animal models. Importantly, no exacerbation of treatment-related toxicity was seen. Importantly, the recently reported preliminary results of a Chinese phase III trial appear to confirm these findings in man. The administration of a novel recombinant endostatin produced in Escherichia coli (Endostar ${ }^{\mathrm{TM}}$ ) in combination with chemotherapy in advanced non-small-cell lung cancer significantly increased response rates and time to progression when compared to chemotherapy alone (Sun et al, 2005). Publication of the full results is eagerly awaited.

More intriguingly, several studies have demonstrated synergy between endostatin and other antiangiogenic agents. Rational combinations determined by analysis of microarray data have been tested successfully in animal models. Cline et al (2002) noted markedly different gene expression profiles when endothelial cells were treated with TNP-470, a synthetic fumagillin analogue, or endostatin and subsequently showed synergistic activity with these agents against Lewis lung carcinoma xenografts. The results of Abdollahi et al (2004) indicated that endostatin downregulated many of the key mediators of VEGF signalling and notably, endostatin and SU5416, a small molecule tyrosine kinase inhibitor of KDR, are synergistic in inhibiting endothelial cell proliferation and the growth and vascularisation of tumour xenografts (Abdollahi et al, 2003). Tumours also grow more rapidly in double tumstatin/TSP-1 knockouts than in mice lacking only one of these molecules, suggesting a broader applicability of the concept of combined antiangiogenic therapy (Sund et al, 2005).

\section{Peptide fragments}

One potential problem with the clinical development of antiangiogenic ECM proteolytic fragments is the requirement to synthesise large quantities of pharmaceutical grade protein. One way of reducing these manufacturing costs may be to identify component peptides from within these molecules that retain antiangiogenic activity. For example, a modified nonapeptide, ABT-510, derived from the second type-1 repeat of TSP-1 has shown promising preclinical and clinical antiangiogenic activity (Haviv et al, 2005). 
Notably, the antiangiogenic properties of tumstatin can be mimicked by a peptide encompassing amino acids 54-132 (Maeshima et al, 2001). The loss of the N-terminal domain of tumstatin in this peptide is potentially of clinical importance as this removes the epitope responsible for GPS.

Endostatin-derived peptides have also been investigated. However, the antiangiogenic activity has been shown to reside in different regions of the molecule by different groups. For instance, a peptide encompassing the secondary heparin-binding site was the minimal active domain in one in vivo study (Olsson et al, 2004) and the N-terminal 29 amino acids critical in another (Tjin Tham Sjin et al, 2005). While both peptides are antiangiogenic, it is not clear whether they function by the same intracellular effector pathways as each other or as parental endostatin.

\section{CONCLUSIONS}

The identification of a series of cryptic proteolytic fragments of ECM components as endogenous angiogenesis inhibitors has shed new light on our understanding of the control of blood vessel development (Nyberg et al, 2005). It is intriguing that integrin- dependent signalling pathways have emerged as critical downstream mediators of the antiangiogenic properties of many of these fragments and that endostatin induces a profound, coordinated response in the angiogenic gene expression profile of endothelial cells (Abdollahi et al, 2004).

The discovery of these molecules has also opened up a significant new avenue in the development of antineoplastic agents. While the clinical development of endostatin as an antiangiogenic drug to date has been disappointing, it has enabled us to learn a number of lessons that could improve the strategy used to take other fragments, for instance tumstatin, through to the clinic. It is desirable that careful biological assays are conducted in a variety of systems and that a defined mechanism of action has been elucidated prior to clinical trials so that trial design can be targeted and appropriate candidate biomarkers can be selected for testing alongside conventional toxicity screening.

The ultimate future of these ECM-derived angiogenesis inhibitors may however lie in the development of rational combinations either with conventional antineoplastic therapy or other antiangiogenic agents.

\section{REFERENCES}

Abdollahi A, Hahnfeldt P, Maercker C, Gröne H-J, Debus J, Ansorge W, Folkman J, Hlatky L, Huber PE (2004) Endostatin's antiangiogenic signaling network. Mol Cell 13: 649-663

Abdollahi A, Lipson KE, Sckell A, Zieher H, Klenke F, Poerschke D, Roth A, Han X, Krix M, Bischof M, Hahnfeldt P, Grone H-J, Debus J, Hlatky L, Huber PE (2003) Combined therapy with direct and indirect angiogenesis inhibition results in enhanced antiangiogenic and antitumor effects. Cancer Res 63: 8890-8898

Bix G, Fu J, Gonzalez EM, Macro L, Barker A, Campbell S, Zutter MM, Santoro SA, Kim JK, Reed CC, Iozzo RV (2004) Endorepellin causes endothelial cell disassembly of actin cytoskeleton and focal adhesions through $\alpha 2 \beta 1$ integrin. J Cell Biol 166: 97-109

Carmeliet P, Jain RK (2000) Angiogenesis in cancer and other diseases. Nature 407: 249-257

Cline EI, Bicciato S, DiBello C, Lingen MW (2002) Prediction of in vivo synergistic activity of antiangiogenic compounds by gene expression profiling. Cancer Res 62: 7143-7148

Davis DW, Shen Y, Mullani NA, Wen S, Herbst RS, O’Reilly M, Abbruzzese JL, McConkey DJ (2004) Quantitative analysis of biomarkers defines an optimal biological dose for recombinant human endostatin in primary human tumors. Clin Cancer Res 10: 33-42

Eder JP, Supko JG, Clark JW, Puchalski TA, Garcia-Carbonero R, Ryan DP, Shulman LN, Proper J, Kirvan M, Rattner B, Connors S, Keogan MT, Janicek MJ, Fogler WE, Schnipper L, Kinchla N, Sidor C, Philips E, Folkman J, Kufe DW (2002) Phase I clinical trial of recombinant human endostatin administered as a short intravenous infusion repeated daily. J Clin Oncol 20: $3772-3784$

Feldman AL, Alexander Jr HR, Yang JC, Linehan WM, Eyler RA, Miller MS, Steinberg SM, Libutti SK (2002) Prospective analysis of circulating endostatin levels in patients with renal cell carcinoma. Cancer 95: 1637-1643

Glenjen N, Mosevoll KA, Bruserud O (2002) Serum levels of angiogenin, basic fibroblast growth factor and endostatin in patients receiving intensive chemotherapy for acute myelogenous leukemia. Int J Cancer 101: $86-94$

Hamano Y, Zeisberg M, Sugimoto H, Lively JC, Maeshima Y, Yang C, Hynes RO, Werb Z, Sudhakar A, Kalluri R (2003) Physiological levels of tumstatin, a fragment of collagen IV $\alpha 3$ chain, are generated by MMP- 9 proteolysis and suppress angiogenesis via $\alpha \mathrm{V} \beta 3$ integrin. Cancer Cell 3: $589-601$

Hanai J, Gloy J, Karumanchi SA, Kale S, Tang J, Hu G, Chan B, Ramchandran R, Jha V, Sukhatme VP, Sokol S (2002) Endostatin is a potential inhibitor of Wnt signaling. J Cell Biol 158: 529-539

Haviv F, Bradley MF, Kalvin DM, Schneider AJ, Davidson DJ, Majest SM, McKay LM, Haskell CJ, Bell RL, Nguyen B, Marsh KC, Surber BW, Uchic JT, Ferrero J, Wang YC, Leal J, Record RD, Hodde J, Badylak SF, Lesniewski RR, Henkin J (2005) Thrombospondin-1 mimetic peptide inhibitors of angiogenesis and tumor growth: design, synthesis and optimization of pharmacokinetics and biological activities. J Med Chem 48: $2838-2846$

Herbst RS, Hess KR, Tran HT, Tseng JE, Mullani NA, Charnsangavej C, Madden T, Davis DW, McConkey DJ, O'Reilly MS, Ellis LM, PLuda J, Hong WK, Abbruzzese JL (2002a) Phase I study of recombinant human endostatin in patients with advanced solid tumors. J Clin Oncol 20: $3792-3803$

Herbst RS, Mullani NA, Davis DW, Hess KR, McConkey DJ, Charnsangavej C, O'Reilly MS, Kim H-W, Baker C, Roach J, Ellis LM, Rashid A, Pluda J, Bucana C, Madden TL, Tran HT, Abbruzzese JL (2002b) Development of biologic markers of response and assessment of antiangiogenic activity in a clinical trial of human recombinant endostatin. J Clin Oncol 20: $3804-3814$

Homandberg GA, Williams JE, Grant D, Schumacher B, Eisenstein R (1985) Heparin-binding fragments of fibronectin are potent inhibitors of endothelial cell growth. Am J Pathol 120: 327-332

Hudson BG, Tryggvason K, Sundaramoorthy M, Neilson E (2003) Alport's syndrome, Goodpasture's syndrome, and type IV collagen. $N$ Engl J Med 348: $2543-2556$

Iizasa T, Chang H, Suzuki M, Otsuji M, Yokoi S, Chiyo M, Motohashi S, Yasufuku K, Sekine Y, Iyoda A, Shibuya K, Hiroshima K, Fujisawa T (2004) Overexpression of collagen XVIII is associated with poor outcome and elevated levels of circulating serum endostatin in non-small cell lung cancer. Clin Cancer Res 10: 5361-5366

Jin H, Varner J (2004) Integrins: roles in cancer development and as treatment targets. Br J Cancer 90: $561-565$

Kalluri R (2003) Basement membranes: structure, assembly and role in tumour angiogenesis. Nat Rev Cancer 3: 422-433

Karumanchi SA, Jha V, Ramchandran R, Karihaloo A, Tsiokas L, Chan B, Dhanabal M, Hanai JI, Venkataraman G, Shriver Z, Keiser N, Kalluri R, Zeng H, Mukhopadhyay D, Chen RL, Lander AD, Hagihara K, Yamaguchi Y, Sasisekharan R, Cantley L, Sukhatme VP (2001) Cell-surface glypicans are low-affinity endostatin receptors. Mol Cell 7: $811-822$

Kim YM, Hwang S, Pyun BJ, Kim TY, Lee ST, Gho YS, Kwon YG (2002) Endostatin blocks VEGF-mediated signaling via direct interaction with KDR/Flk-1. J Biol Chem 277: $27872-27879$

Kisker O, Becker CM, Prox D, Fannon M, D’Amato R, Flynn E, Fogler WE, Sim BK, Allred EN, Pirie-Shepherd SR, Folkman J (2001) Continuous administration of endostatin by intraperitoneally implanted osmotic pump improves the efficacy and potency of therapy in a mouse xenograft tumor model. Cancer Res 61: 7669-7674

Klement G, Kikuchi L, Kieran M, Almog N, Yip T, Folkman J (2004) Early tumor detection using platelet uptake of angiogenesis regulators. Blood 104: 839 a 
Kulke M, Bergsland E, Ryan DP, Clark JW, Enzinger PC, Michelini A, Kinsella K, Fogler W, Venook A, Fuchs C (2003) A phase II open-label, safety, pharmacokinetic and efficacy study of recombinant human endostatin in patients with advanced neuroendocrine tumors. Proc Am Soc Clin Oncol 22: 958a

Lee SJ, Jang JW, Kim YM, Lee HI, Jeon JY, Kwon YG, Lee ST (2002) Endostatin binds to the catalytic domain of matrix metalloproteinase-2. FEBS Lett 519: $147-152$

MacDonald NJ, Shivers WY, Narum DL, Plum SM, Wingard JN, Fuhrmann SR, Liang H, Holland-Linn J, Chen DH, Sim BK (2001) Endostatin binds tropomyosin. A potential modulator of the anti-tumor activity of endostatin. I Biol Chem 276: 25190-25196

Maeshima Y, Manfredi M, Reimer C, Holthaus KA, Hopfer H, Chandamuri BR, Kharbanda S, Kalluri R (2001) Identification of the anti-angiogenic site within vascular basement membrane-derived tumstatin. J Biol Chem 276: $15240-15248$

Marneros AG, Olsen BR (2005) Physiological role of collagen XVIII and endostatin. FASEB J 19: 716-728

Nyberg P, Xie L, Kalluri R (2005) Endogenous inhibitors of angiogenesis. Cancer Res 65: $3967-3979$

O'Reilly MS, Boehm T, Shing Y, Fukai N, Vasios G, Lane S, Flynn E, Birkhead JR, Olsen BR, Folkman J (1997) Endostatin: an endogenous inhibitor of angiogenesis and tumor growth. Cell 88: 277-285

Olsson A-K, Johansson I, Akerud H, Einarsson B, Christofferson R, Sasaki T, Timpl R, Claesson-Welsh L (2004) The minimal active domain of endostatin is a heparin-binding mutant that mediates inhibition of tumor vascularization. Cancer Res 64: $9012-9017$

Pezzella F, Pastorino U, Tagliabue E, Andreola S, Sozzi G, Gasparini G, Menard S, Gatter KC, Harris AL, Fox S, Buyse M, Pilotti S, Pierotti M, Rilke F (1997) Non-small-cell lung carcinoma tumor growth without morphological evidence of neo-angiogenesis. Am J Pathol 151: 1417 1423

Plum SM, Hanson AD, Volker KM, Vu HA, Sim BK, Fogler WE, Fortier AH (2003) Synergistic activity of recombinant human endostatin in combination with adriamycin: analysis of in vitro activity on endothelial cells and in vivo tumor progression in an orthotopic murine mammary carcinoma model. Clin Cancer Res 9: 4619-4626

Rosner GL, Stadler W, Ratain MJ (2002) Randomized discontinuation design: application to cytostatic antineoplastic agents. J Clin Oncol 20: $4478-4484$
Shi W, Teschendorf C, Muzyczka N, Siemann DW (2003) Gene therapy delivery of endostatin enhances the treatment efficacy of radiation. Radiother Oncol 66: 1-9

Sudhakar A, Sugimoto H, Yang C, Lively J, Zeisberg M, Kalluri R (2003) Human tumstatin and human endostatin exhibit distinct antiangiogenic activities mediated by $\alpha \mathrm{v} \beta 3$ and $\alpha 5 \beta 1$ integrins. Proc Natl Acad Sci USA 100: $4766-4771$

Sun Y, Wang J, Liu Y, Song X, Zhang Y, Li K, Zhu Y, Zhou Q, You L, Yao C (2005) Results of a phase III trial of Endostar TM (rh-endostatin, YH-16) in advanced non-small cell lung cancer patients. Proc ASCO 23: 7138a

Sund M, Hamano Y, Sugimoto H, Sudhakar A, Soubosakos M, Yerramalla U, Benjamin LE, Lawler J, Kieran M, Shah A, Kalluri R (2005) Function of endogenous inhibitors of angiogenesis as endothelium-specific tumor suppressors. Proc Natl Acad Sci USA 102: 2934-2939

Thomas JP, Arzoomanian RZ, Alberti D, MArnocha R, Lee F, Friedl A, Tutsch K, Dresen A, Geiger P, PLuda J, Fogler W, Schiller JH, Wilding G (2003) Phase I pharmacokinetic and pharmacodynamic study of recombinant human endostatin in patients with advanced solid tumors. J Clin Oncol 21: 223-231

Tjin Tham Sjin RM, Satchi-Fainaro R, Birsner AE, Ramanujam S, Folkman J, Javaherian K (2005) A 27-amino acid synthetic peptide corresponding to the $\mathrm{NH}_{2}$-terminal zinc-binding domain of endostatin is responsible for its antitumor activity. Cancer Res 65: 3656-3663

Van der Schaft DWJ, Seftor REB, Seftor EA, Hess AR, Gruman LM, Kirschmann DA, Yokoyama Y, Griffioen AW, Hendrix MJC (2004) Effects of angiogenesis inhibitors in vascular network formation by human endothelial and melanoma cells. J Natl Cancer Inst 96: 1473-1477

Wickström SA, Alitalo K, Keski-Oja J (2003) Endostatin associates with lipid rafts and induces reorganization of the actin cytoskeleton via downregulation of RhoA activity. J Biol Chem 278: 37895-37901

Yang Q, Rasmussen SA, Friedman JM (2002) Mortality associated with Down's syndrome in the USA from 1983 to 197: a population based study. Lancet 359: 1019-1025

Yokoyama Y, Ramakrishnan S (2004) Addition of integrin binding sequence to a mutant human endostatin improves inhibition of tumor growth. Int J Cancer 111: 839-848

Zorick TS, Mustacchi Z, Bando SY Zatz M, Moreira-Filho CA, Olsen B, Passos-Bueno MR (2001) High serum endostatin levels in Down's syndrome: implications for improved treatment and prevention of solid tumours. Eur J Hum Genet 9: $811-814$ 